Илья Васькин

\title{
ВЛИЯНИЕ РЕЗУЛЬТАТОВ ПРЕЗИДЕНТСКИХ ВЫБОРОВ НА ЭКОНОМИЧЕСКУЮ ПОДДЕРЖКУ РЕГИОНОВ В ОПЕКУНСКИХ РЕЖИМАХ: КЕЙС ИРАНА 2005-2013 ГГ.
}

Статья посвящена роли поддержки инкумбента на президентских выборах в финансировании регионов в опекунских режимах на примере Ирана 2005-2013 гг. Данные включают 242 наблюдения по 31 регионам за восемь лет. Исследование основано на теориях поддержки ядерного электората и теории колеблющихся избирателей. В статье проанализирована трансформация распределительной политики в Иране до 2013 г. В результате корреляционного и регрессионного анализа выявлено, что между электоральной поддержкой инкумбента на президентских выборах и выдачей краткосрочных кредитов регионам существует значимая отрицательная связь. В свою очередь, значимая связь между поддержкой инкумбента на президентских выборах и выдачей долгосрочных кредитов на развитие не обнаружена. У таких результатов может быть два объяснения. Во-первых, правящая коалиция может представлять, что ядерный электорат инкумбента устойчив, поэтому необходимо обращаться к сторонникам политических оппонентов. Во-вторых, причиной является стремление решать в первую очередь экономические и социальные проблемы подобные бедности, низкому уровню грамотности, безработице, чтобы усилить собственную поддержку в соответствующих регионах за счет их решения. Эти результаты также могут отражать ориентацию инкумбента на нелояльные регионы и улучшение условий в них с целью дальнейшего повышения собственного рейтинга и, шире, решение проблемы низкого уровня жизни. Кроме того, он также может ориентироваться на привлечение сторонников своих оппонентов, что возможно только в случае рациональности избирателей. Однако результаты данного исследования могут представлять и исключительный

Илья Андреевич Васькин- аспирант, Аспирантская школа по политическим наукам, стажёр-исследователь, Институт институциональных исследований, Национальный исследовательский университет «Высшая школа экономики», Москва, Россия. Электронная почта: ivaskin@hse.ru 
случай, характерный либо для конкретного президента, либо для политического режима Ирана.

Ключевые слова: выборы, финансирование регионов, Иран, Махмуд Ахмадинежад, количественный анализ

DOI: 10.17323/727-0634-2020-18-2-313-330

Проблема финансирования регионов в зависимости от поддержки победивших президента/партии является проработанной темой в области политической экономии институтов и роста. Основной пласт литературы по теме концентрируется на странах с классическими демократическими и авторитарными политическими режимами, включая гибридные. Однако до сих пор не рассмотрены режимы, которые Стивен Левицки и Лукан Вэй (Levitsky, Way 2010:6) называют «опекунскими» (tutelary)- т.е. режимы, в которых выборы конкурентны, но власть избираемых правительств ограничена неизбираемой религиозной, монархической или военной властью.

Согласно данной классификации, к ним относится и Иран. С одной стороны, в этой стране проводятся президентские, парламентские выборы, выборы в городские советы. Кроме того, происходят выборы в состоящий из представителей духовенства Совет экспертов, из чьего состава выдвигается Верховный руководитель Ирана. Их результаты непредсказуемы. С другой стороны, основным ограничением является невозможность принимать в них участие для кандидатов, чья программа не соответствует доктрине Велаят-э-факих, либо в случаях, когда консервативный по своему составу Совет стражей Конституции запрещает выдвигаться кандидатам из реформаторского лагеря (Beeman 2013:405; Ghobadzadeh, Rahim 2016).

Иран, будучи опекунским режимом, совмещает в себе демократические и авторитарные элементы. Над всеми органами власти стоит Верховный руководитель, который является духовным лицом, ключевые решения по ряду вопросов принимает духовенство. Президенты стабильно менялись, как правило, после двух сроков, за исключением выборов 1980 и 1981 гг. ${ }^{1}$ После выборов нового президента они или уходили в оппозицию или занимали место в другом институте власти. Таким образом, существует надстройка в формате «исламских» органов власти, которые стоят над демократической по своей природе системой и контролируют доступ к участию в ключевых политических процессах. В силу того, что духовенство, составляющее ядро правящей элиты страны, расколото по ключевым вопросам развития страны (Rakel 2009), разные его группы вступают в союзы с военными и технократами для продвижения собственных интересов и собственной политики (Golkar 2016). Но поскольку проводимая политика

\footnotetext{
1 Избранный в 1980 г. президент Абольхасан Банисадр изгнан в 1981 г. из-за конфликта с аятоллой Хомейни. Президент Али Раджаи, избранный в 1981 г., убит.
} 
напрямую влияет на популярность этих союзов, именно избиратели посредством выборов определяют какая группа будет более влиятельной. В частности, Махмуд Ахмадинежад представлял интересы союза консервативного духовенства и военных, недовольных радикально реформаторской политикой президента Мохаммада Хатами.

Согласно Конституции Ирана 1979 г. с поправками 1989 г., президент выбирается населением страны (Constitution 1979: гл. 9, ст. 114). Однако список кандидатов проверяется на соответствие критериям Советом стражей Конституции, а финальный список претендентов подтверждает Верховный лидер Ирана (гл. 8, ст. 110). Все кандидаты должны соответствовать минимальным требованиям: иранское происхождение, гражданство Ирана, распорядительность и организационные способности, достойная биография и набожность, религиозность, вера в основы Исламской Республики и принадлежность к официальной религии страны (гл. 9, ст. 115). В итоге в выборах участвуют от двух до десяти кандидатов. Доля допущенных до выборов с 1981 г. составляет в среднем 2,9\%. Единственным серьезным исключением являются выборы 1980 г, участвовать в которых было разрешено 96 кандидатам из 124 зарегистрированных, или 74\%.

\section{Голосование на выборах и экономическая поддержка регионов}

Существуют две теории распределения бюджетных трансфертов: теория поддержки ядерного электората (Cox, McCubbins 1986) и теория поддержки колеблющихся избирателей (Lindbeck, Weibull 1987), детально описанные коллективом исследователей (Marques et al. 2016). Обе теории основаны на допущениях, что руководители партий стремятся повысить свою поддержку, выраженную в доле голосов, получаемых ими на выборах. В этих моделях трансферы являются неточным инструментом, так как лидеры партий могут финансировать только группы и регионы, а не индивидов. Основной проблемой политики распределения для данных моделей является вопрос, какую группу поддерживать.

Один подход (Lindbeck, Weibull 1987) доказывает, что политики поддерживают колеблющихся избирателей, со слабо выраженной партийной близостью. Поскольку предполагается, что ядерный электорат и так будет голосовать за соответствующего политика, необходимо привлекать колеблющихся избирателей, чтобы увеличить свою поддержку. Данная модель содержит два допущения: (1) отправляемые и получаемые соответствующей группой ресурсы совпадают; (2) избиратели не отказываются от своих позиций после получения ресурсов. Другая модель (Cox, McCubbins 1986) ставит под сомнение оба допущения, обращая внимание на то, что любое вкладывание ресурсов вне ядерного электората, т.е. поддержка тех, кто слабо поддерживает соответствующих политиков, является риском. 
Исследования, проведенные на материале разных стран, предлагают результаты как в пользу одной теории, так и в пользу другой. Как показали Сюзан Стоукс с соавторами (Stokes et al. 2013), в разных политических режимах электоральная поддержка инкумбента на выборах и финансирование регионов варьируются от страны к стране и от режима к режиму. В частности, в гибридных режимах подобно Бразилии, Аргентине, Перу, Мексике, России в основном поддерживаются лояльные регионы/муниципалитеты. При этом лояльность может определяться как уровень поддержки определенной партии или кандидата на выборах, и как наличие не аффилированного с правящей группой главы столицы региона или муниципалитета. Вместе с тем согласно Стоукс, в тех же странах иногда проводится политика поддержки колеблющихся избирателей.

В демократиях, в свою очередь, преобладает распределение ресурсов, основанное на поддержке колеблющихся: такую логику можно наблюдать в США, Канаде, Австралии, Испании, Португалии, Швеции, Индии, что также не мешает политикам этих стран в отдельных случаях поддерживать лояльных избирателей. В моменты кризисов в режимах подобного рода логика поддержки колеблющихся смещается на поддержку ядерного электората, как это было в США в штате Флорида в 2004 г. после урагана шестого уровня опасности (Chen 2013).

Таким образом, на данный момент в литературе отсутствует консенсус по поводу того, как политический режим влияет на финансирование регионов в связи с политической лояльностью. При этом отметим, что в демократиях в среднем чаще фиксируется поддержка колеблющихся избирателей, а в гибридных режимах - лояльных. Учитывая, что в Иране президент отвечает за бюджетную политику, а выборы в рамках политической системы Ирана относительно свободные и честные, за исключением вызвавших дискуссию и протестное движение президентских выборов 2009 г. (Вeeman 2013:406), гипотеза данного исследования формулируется следующим образом:

H1: поддержка инкумбента на президентских выборах отрицательно связана с финансированием провинций в формате выдачи им кредитов.

\section{Бюджетный процесс и распределение ресурсов в Иране}

В этом контексте важно проанализировать социальную политику Ирана, т.к. это может помочь объяснить распределение ресурсов между регионами. Следует уточнить, что именно президент отвечает за бюджетную политику страны (Constitution 1979: гл. 9, ст. 126). Как отмечает ряд исследователей (Kamal et al. 2015; Harris 2017), целью долгосрочной политики группы, находящейся у власти в Иране, помимо сохранения собственной 
позиции, является борьба с бедностью и повышение уровня жизни в стране с помощью пара-государственных организаций (Jawad, Yakut-Cakar 2010). Им также оказывают поддержку религиозные организации, по факту являющиеся парагосударственными (Alamdari 2005). Эти организации имеют большие, формально негосударственные бюджеты, что фактически ведет к более высоким затратам на решение социальных вопросов (Esfahani, Taheripour 2002). Казем Алямдари (Alamdari 2005: 1293) приводит в качестве примера Благотворительный комитет Имама (Imam Charity Committee), бюджет которого был четвертым в Иране после Министерства обороны, полиции и Корпуса стражей Исламской революции (КСИР). На начало 2000 -х гг. его структура на $75 \%$ состояла из госфинансирования, остальные деньги были частными.

Кроме того, иранская элита стремилась обеспечить экономический рост без увеличения неравенства доходов бедных и богатых. Как показывает в своем исследовании Джавад Салехи-Ифахани (Salehi-Isfahani 2006), в период с 1990 по 2005 гг. в стране значительно вырос средний уровень доходов, восстановившись до уровня, предшествовавшего Исламской революции 1979-1980 гг. В результате этой политики снизился уровень бедности, вырос уровень дохода, потребления, доступа к базовым благам. Кроме того, значительно расширился слой людей, обеспеченных такими публичными благами, как электричество и чистая вода, что привело к росту уровня жизни в целом (Ibid).

Во время президентских сроков Махмуда Ахмадинежада (2005-2013) подход к распределению ресурсов был изменен. Как показывает Надер Хабиби (Habibi 2015), президент считал, что логика распределения ресурсов между провинциями до его президентских сроков была несправедливой. Поэтому каждые 23 дня он овершал визиты в слаборазвитые регионы страны для обеспечения экономической поддержки проектам развития в небольших городах и деревнях. Эта политика имела как положительные, так и отрицательные последствия. С одной стороны, она действительно привела к сокращению неравенства. С другой, его критики отмечали, что Ахмадинежад игнорирует пятилетний план развития и распределяет ресурсы ad hoc.

\section{Данные и методы}

Все данные исследования основаны на иранском календарном годе или адаптированы для него, потому что социально-экономическая статистика по провинциям Ирана доступна только в формате данного календаря. Он начинается 21 марта и заканчивается 20 марта. Для того чтобы конвертировать его в григорианский календарный год, необходимо добавить к значению иранского календарного года 622 года, если необходимая дата относится к периоду до 20 марта включительно, или же добавить 621 год, если необходимая дата относится к периоду после 20 марта. В выборке данных для этой статьи восемь иранских календарных лет: 1384-1391 гг. (2005-2013 гг). 
Основным источником социально-экономических данных по Ирану на уровне провинций являются Статистические ежегодники Ирана (Statistical Centre... 2012-2015). Из них, в частности, извлекаются основные зависимые переменные для данного исследования (описательную статистику см. в приложении, табл. 1). Экономическая поддержка регионов Ирана определяется через сумму млн риалов, выделенных на душу населения согласно двум показателям соответствующего финансирования.

(1) Кредиты на развитие- относятся к кредитам, выделенным на конкретные операции и услуги, которые осуществляются на основе технических, социальных и экономических исследований правительственной организацией. Эти операции и услуги реализуются в течение определенного периода времени с конкретным бюджетом для реализации целей пятилетнего плана развития в качестве фиксированных инвестиций или проведения исследования по созданию основного капитала. Необходимые ресурсы для проведения этих операций и услуг финансируются за счет основного капитала (Statistical Centre... 2013 b: 788).

(2) Текущие кредиты-кредиты, рассмотренные в пятилетнем плане развития в целом, и в государственном бюджете по частям для покрытия текущих расходов правительства, а также поддержания его социальноэкономической деятельности (Ibid). Зависимыми переменными в данном исследовании, соответственно, выступают кредиты на развитие и текущие кредиты по отдельности, а также в сумме, скорректированные на численность населения в регионе.

В качестве основной независимой переменной выступает процент голосов, отданных за Махмуда Ахмадинежада на президентских выборах 2005 и 2009 гг. Поскольку выборы 2005 г. состояли из двух туров, а также из-за того, что основная борьба развернулась во втором, в работе для 2005-2009 гг. использованы результаты второго тура, а не первого. Источником данных по результатам выборов являются официальные данные (Iran Data Portal 2018d, e). Из статистических ежегодников были также извлечены данные по доле трудоспособного населения и уровню безработицы. Безработица там представлена как доля работающего населения относительно трудоспособного (трудоспособным считается человек начиная с 14 лет). Данные по урбанизации были взяты из Национальной переписи населения и жилья (Statistical Centre... 2011). Часть данных по урбанизации восстановлена с помощью линейного тренда, т.е. значение переменной 2006 г. вычтено из значения 2011 г., разделено на пять. Итоговый результат последовательно прибавлялся к каждому из соответствующих годовых значений. Это шаг предпринят потому, что в данном источнике доступны только две точки: 1385 г. (2006-2007 гг.) и 1390 г. (2011-2012 гг.). В расчетах использовались официальные данные по валовому региональному продукту (ВРП) на душу населения (Iran Data Portal 2018a, b, c), а доля нефти в ВРП посчитана автором статьи вручную, что позволило определить роль этого 
ресурса в экономике провинций. Для измерения ВВП используются млрд иранских риалов. Кроме того, из Статистических ежегодников извлечена информация по доле грамотного населения. Поскольку эти данные основаны на переписях 2005 и 2010 гг., недостающие-реконструированы.

В Иране действует дискриминационная этническая политика по отношению к неперсидским группам. В частности, ограничивается использование неперсидских языков, на местном уровне в регионах с неперсидским большинством ставят руководителями персов (Saleh 2013). Соответственно, эта политика также может влиять и на распределение ресурсов на уровне регионов, уменьшая количество распределенных ресурсов в регионы, где нет доминирования персов. Данные по этносам были взяты из отчета (Iran Data Portal 2018f). Доля персов посчитана на основе этих данных. В силу того, что опрос не затрагивал 1384-1387 гг. (2005-2008 гг.), автор использовал значения предыдущих годов. Кроме того, часть данных представляет собой выбросы (слишком малые или слишком большие значения), которые заменены на среднее арифметическое соответствующих лет.

Основными методами в данной работе выступают корреляционный и регрессионный анализ с фиксированными эффектами. Корреляционный анализ обеспечил первичную оценку влияния поддержки Махмуда Axмадинежада на выборах на уровне регионов на их финансирование. Регрессионный анализ позволил уточнить, какова роль этого фактора в контексте всех остальных, описаных выше. Данный метод типичен для подобных исследований (Veiga, Pinho 2007; Simon-Cosano et al. 2013), т. к. позволяет определить наличие связи между зависимой и независимыми переменными в случаях нормального распределения данных.

\section{Результаты}

Статистика финансирования регионов за 2005-2013 гг. (рис. 1) показывает, что в 2005-2009 гг. преобладали текущие кредиты, а в 2009-2013 гг. основная часть экономической поддержки регионов шла за счет кредитов на развитие. Этот эффект можно объяснить реформой региональных правительств в связи с IV пятилетним планом развития (2005-2009), разработкой региональных программ развития и создания соответствующей инфраструктуры для их реализации. Резкий рост кредитов на развитие после 2009 г. можно объяснить субсидиарной реформой 2010 г. До нее государство инвестировало большие суммы денег в энергетической сектор (нефть и газ). В процессе реформы они были заменены на дивиденды от платы за энергию. Сохраненные в результате этой реформы ресурсы позволили сэкономить большое количество средств и инвестировать их в развитие страны (Guillaume et al. 2011). Однако она имела в основном краткосрочные эффекты, что, вместе с санкциями, привело к общему снижению финансирования регионов и торможению их долгосрочного развития (Demirkol et al. 2014). 


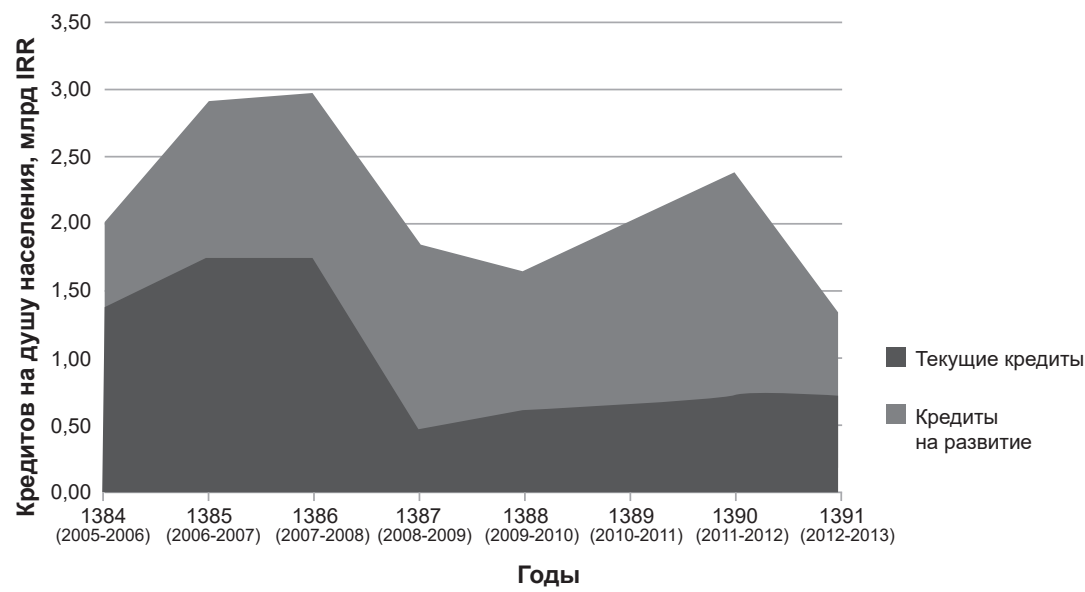

Рисунок 1. Финансирование регионов Ирана по годам, 2005-2013 гг.

Если же проанализировать финансирование регионов на уровне провинций (рис. 2), то оказывается, что текущие кредиты во всех провинциях относительно близки друг к другу по объему. Однако кредиты на развитие очень сильно колеблются в зависимости от региона. Это значит, что в одни регионы целенаправленно инвестируются средства для развития, в то время как в другие они инвестируются по остаточному принципу. При этом основная часть денег в пересчете на душу населения вкладывалась в первую очередь в бедные провинции, а Тегеран, Альборз и другие практически не финансировались.

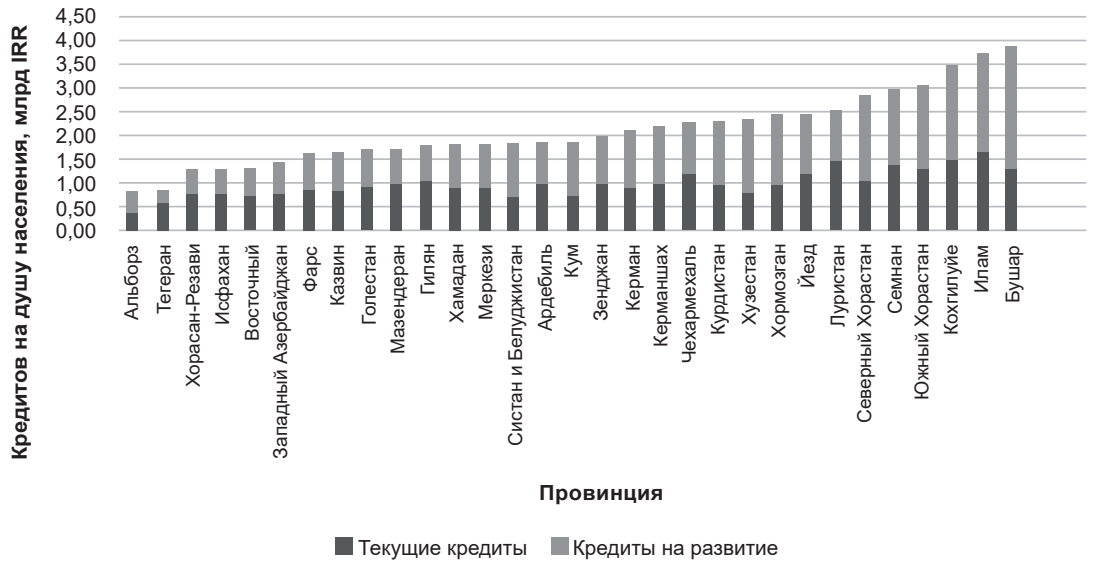

Рисунок 2. Финансирование регионов Ирана по провинциям, 2005-2013 гг. 
Следующим этапом является анализ связи между результатами президентских выборов и финансированием регионов. На первом этапе применялся корреляционный анализ (см. приложение, табл. 2). Финансирование регионов Ирана оказывается не связано с тем, какую поддержку они оказали победившему кандидату на президентских выборах. Это характерно как для текущих кредитов, как и для кредитов на развитие. При этом наиболее близки к наличию значимой связи только текущие, у которых данный параметр имеет значение 0,074 .

На следующем этапе следует многоуровневый анализ данных (см. приложение, табл. 3) с помощью линейной регрессии для всех трех видов финансирования регионов. Это позволяет выявить роль поддержки инкумбента на выборах с учетом контролей. Проведенный анализ показывает, что имеется связь между результатами выборов и финансированием регионов в плане текущих кредитов и кредитов в целом, и эта связь отрицательная. Кредиты на развитие никак не связаны с долей голосов, которую получил инкумбент на выборах 2005 и 2009 гг. Это может быть объяснено специфической моделью иранского государства всеобщего благосостояния, описанной Кеваном Харрисом (Harris 2017). Она ориентирована на создание нового среднего класса и немонетарные способы повышения благосостояния. Соответственно, в этой модели экономические интересы являются приоритетом по сравнению с политическими.

Важно, однако, что подобный подход мог помочь привлечь на сторону инкумбента его соперников. Это было бы возможно в случае успешного развития регионов. Но такая ситуация осуществима при наличии следующего допущения: ядерный электорат рационален, он может менять свою позицию в случае наличия доказательств эффективности политики оппонентов; либо сами политики меняют свою позицию.

\section{Проверка на робастность}

Модели, представленные выше, проверены на робастность: данные разбиты на два периода, согласно президентским срокам Махмуда Ахмадинежада: 2005-2009 гг. (см. приложение, табл. 4) и 2009-2013 гг. (см. приложение, табл. 5). Как показывает анализ, закономерности в целом сохраняются. Во время обоих сроков Ахмадинежада доля голосов, отданных за него, была отрицательно связана с выдачей текущих кредитов регионам. При этом во время первого срока его поддержка на уровне регионов также имела отрицательную связь с кредитами на развитие. Результаты показывают, что в целом электоральная поддержка Махмуда Ахмадинежада имела негативный эффект на финансирование провинций Ирана.

Эти результаты являются контринтуитивными, особенно в контексте того, что в развивающихся странах преобладают патрон-клиентские отношения, которые предполагают поддержку узких групп интересов. Тем 
не менее в данном случае наблюдается противоположный эффект. Это можно объяснить тем, что правящая коалиция консервативно настроенного духовенства могла считать, что у этого инкумбента (Ахмадинежада) поддержка является высокой самой по себе. Соответственно, надо привлекать на свою сторону тех, кто его не поддерживает или находится в оппозиции, а значит, создавать новые рабочие места, повышать грамотность населения, привлекать сельских жителей в город и т.п.

\section{Заключение}

Исследование определило форму связи между поддержкой президента на выборах в Иране и финансированием регионов в 2005-2013 гг. В качестве зависимых переменных использовались текущие кредиты, кредиты на развитие и кредиты в целом, в качестве основной независимой переменнойдоля голосов, которые получил инкумбент на выборах 2005 и 2009 гг. Были выявлены наименее и наиболее финансируемые регионы.

Проведенный анализ показал, что чем активнее регион поддерживал инкумбента на выборах, тем меньше текущих кредитов и кредитов в целом он получал. При этом поддержка никак не влияла на кредиты на развитие. Эти результаты могут отражать ориентацию президента на нелояльные регионы и улучшение условий в них с целью дальнейшего повышения собственного рейтинга и, шире, решения проблемы низкого уровня жизни. Иными словами, Ахмадинежад ориентировался на привлечение на свою сторону сторонников оппонентов, что обусловлено, однако, рациональностью избирателей.

Проведенный анализ показал, что в опекунских режимах работает теория поддержки колеблющихся избирателей. Однако учитывая явный недостаток данных, подобная ситуация может быть как спецификой конкретно периода 2005-2013 гг., так и спецификой самого Ирана. Исследование является первой попыткой ответить на этот вопрос в контексте опекунских режимов.

\section{Выражение признательности}

Статья подготовлена по результатам исследования в рамках Программы фундаментальных исследований НИУ ВШЭ и с использованием средств субсидии в рамках государственной поддержки ведущих университетов Российской Федерации «5-100». 
Таблица 1

Описательная статистика переменных

\begin{tabular}{|c|c|c|c|c|c|}
\hline & $z$ & 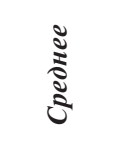 & 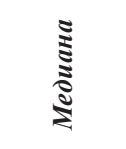 & 㐔 & 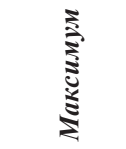 \\
\hline Текущие кредиты & 240 & 1,01 & 0,80 & 0,21 & 3,02 \\
\hline Кредиты на развитие & 240 & 1,13 & 1,03 & 0,08 & 5,91 \\
\hline Кредиты в целом & 240 & 2,15 & 1,97 & 0,31 & 6,58 \\
\hline Население, чел. & 240 & 2367695 & 1617000 & 549000 & 12358000 \\
\hline $\begin{array}{l}\text { Доля трудоспособного } \\
\text { населения,\% }\end{array}$ & 240 & 38,29 & 37,95 & 26,10 & 48,60 \\
\hline Безработица,\% & 240 & 11,56 & 11,25 & 5,20 & 20,50 \\
\hline Доля нефти в ВРП,\% & 240 & 10,64 & 0,50 & 0,00 & 90,27 \\
\hline $\begin{array}{l}\text { ВРП на душу } \\
\text { населения, млрд IRR }\end{array}$ & 240 & 51331,22 & 38256,63 & 2256,41 & 250248,31 \\
\hline Урбанизация,\% & 240 & 63,60 & 61,14 & 46,52 & 95,46 \\
\hline Доля грамотных,\% & 240 & 83,07 & 82,60 & 67,28 & 91,46 \\
\hline Доля персов,\% & 240 & 42 & 32 & 0 & 99 \\
\hline Ахмадинежад,\% & 239 & 62,63 & 64,57 & 37,69 & 77,78 \\
\hline Всего & 239 & & & & \\
\hline
\end{tabular}

Таблица 2

Коэффициент корреляции: результаты президентских выборов и финансирование регионов Ирана, 2005-2013

\begin{tabular}{ll|r|r|r}
\hline & & & \\
& & & \\
& & & \\
Ахмадинежад,\% & Корреляция Пирсона & $-0,116$ & 0,091 & $-0,003$ \\
& Знач. (2-х сторонняя) & 0,074 & 0,160 & 0,965 \\
$\mathrm{~N}$ & 240 & 240 & 239 \\
\hline
\end{tabular}


Таблица 3

Результаты линейной регрессии: зависимые переменные- кредиты регионам Ирана, 2005-2013

\begin{tabular}{|c|c|c|c|}
\hline & \multicolumn{3}{|c|}{ Зависимая переменная } \\
\hline & 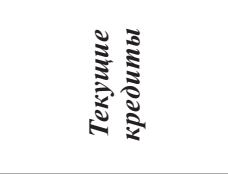 & 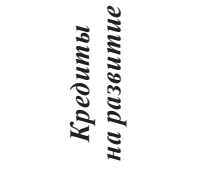 & 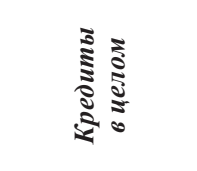 \\
\hline & (1) & (2) & (3) \\
\hline \multirow[t]{2}{*}{ Ахмадинежад,\% } & $-0.008^{* * *}$ & -0.004 & $-0.011^{* * *}$ \\
\hline & $(0.002)$ & $(0.004)$ & $(0.004)$ \\
\hline \multirow[t]{2}{*}{ Логарифм населения, чел. } & $-0.294^{* * *}$ & $-0.408^{* * *}$ & $-0.707^{* * *}$ \\
\hline & $(0.02)$ & $(0.047)$ & $(0.054)$ \\
\hline \multirow{2}{*}{$\begin{array}{l}\text { Доля трудоспособного } \\
\text { населения. \% }\end{array}$} & 0.0004 & $-0.018^{*}$ & $-0.018^{*}$ \\
\hline & $(0.004)$ & $(0.009)$ & $(0.011)$ \\
\hline \multirow[t]{2}{*}{ Безработица, \% } & $0.021^{* * *}$ & -0.004 & 0.017 \\
\hline & $(0.005)$ & $(0.011)$ & $(0.013)$ \\
\hline \multirow{2}{*}{$\begin{array}{l}\text { Логарифм ВBП на душу } \\
\text { населения, млн IRR }\end{array}$} & 0.04 & $0.208^{* * *}$ & $0.246^{* * *}$ \\
\hline & $(0.028)$ & $(0.065)$ & $(0.074)$ \\
\hline \multirow[t]{2}{*}{ Урбанизация, \% } & $-0.006^{* * *}$ & 0.001 & -0.005 \\
\hline & $(0.001)$ & $(0.003)$ & $(0.004)$ \\
\hline \multirow[t]{2}{*}{ Доля нефти в ВВП, \% } & 0.001 & $0.007^{* * *}$ & $0.008^{* * *}$ \\
\hline & $(0.001)$ & $(0.002)$ & $(0.002)$ \\
\hline \multirow[t]{2}{*}{ Доля грамотных, \% } & $0.027^{* * *}$ & $-0.038^{* * *}$ & -0.011 \\
\hline & $(0.006)$ & $(0.013)$ & $(0.015)$ \\
\hline \multirow[t]{2}{*}{ Доля персов, \% } & -0.0003 & $0.004^{* * *}$ & $0.003^{* * *}$ \\
\hline & $(0.0005)$ & $(0.001)$ & $(0.001)$ \\
\hline Годы & Да & Да & Да \\
\hline \multirow[t]{2}{*}{ Константа } & $3.563^{* * *}$ & $8.277^{* * *}$ & $11.894^{* * *}$ \\
\hline & $(0.422)$ & $(0.981)$ & $(1.117)$ \\
\hline Количество наблюдений & 240 & 240 & 239 \\
\hline Скорректированный $\mathrm{R}^{2}$ & 0.89 & 0.61 & 0.74 \\
\hline Residual Std. Error & $0.19(\mathrm{df}=223)$ & $0.44(\mathrm{df}=223)$ & $0.5(\mathrm{df}=222)$ \\
\hline F Statistic & $124.94^{* * *}(\mathrm{df}=16$ & $24.62^{* * *}(\mathrm{df}=16 ;$ & $42.75^{* * *}(\mathrm{df}=16$ \\
\hline
\end{tabular}

Примечания:

${ }^{*} \mathrm{p}^{* *} \mathrm{p}^{* * *} \mathrm{p}<0.01$ 
Таблица 4

Результаты линейной регрессии: зависимые переменные- кредиты регионам Ирана, 2005-2009

\begin{tabular}{|c|c|c|c|}
\hline & \multicolumn{3}{|c|}{ Зависимая переменная } \\
\hline & 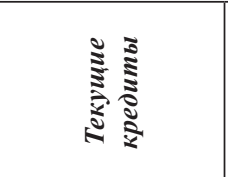 & 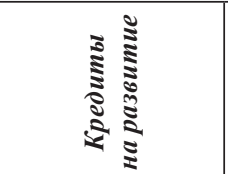 & 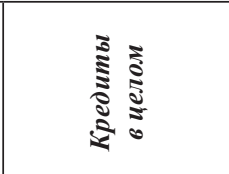 \\
\hline & (1) & (2) & (3) \\
\hline \multirow[t]{2}{*}{ Ахмадинежад, \% } & $-0.011^{* * *}$ & $-0.007^{* *}$ & $-0.018^{* * *}$ \\
\hline & $(0.003)$ & $(0.004)$ & $(0.005)$ \\
\hline \multirow[t]{2}{*}{ Логарифм населения, чел } & $-0.301^{* * *}$ & $-0.405^{* * *}$ & $-0.711^{* * *}$ \\
\hline & $(0.036)$ & $(0.048)$ & $(0.067)$ \\
\hline \multirow{2}{*}{$\begin{array}{l}\text { Доля трудоспособного } \\
\text { населения, \% }\end{array}$} & 0.006 & -0.007 & -0.002 \\
\hline & $(0.007)$ & $(0.009)$ & $(0.013)$ \\
\hline \multirow[t]{2}{*}{ Безработица, \% } & $0.034^{* * *}$ & -0.006 & 0.028 \\
\hline & $(0.01)$ & $(0.013)$ & $(0.018)$ \\
\hline \multirow{2}{*}{$\begin{array}{l}\text { Логарифм ВBП на душу } \\
\text { населения, млн IRR }\end{array}$} & -0.005 & $0.117^{*}$ & 0.111 \\
\hline & $(0.047)$ & $(0.063)$ & $(0.087)$ \\
\hline \multirow[t]{2}{*}{ Урбанизация, \% } & $-0.006^{* * *}$ & -0.003 & $-0.009 * * *$ \\
\hline & $(0.002)$ & $(0.003)$ & $(0.004)$ \\
\hline \multirow[t]{2}{*}{ Доля нефти в ВВП, \% } & 0.001 & $0.01^{* * *}$ & $0.011^{* * *}$ \\
\hline & $(0.001)$ & $(0.002)$ & $(0.002)$ \\
\hline \multirow[t]{2}{*}{ Доля грамотных, \% } & $0.036^{* * *}$ & -0.018 & 0.018 \\
\hline & $(0.009)$ & $(0.012)$ & $(0.016)$ \\
\hline \multirow[t]{2}{*}{ Доля персов, \% } & $-0.002 * *$ & $0.004^{* * *}$ & 0.002 \\
\hline & $(0.001)$ & $(0.001)$ & $(0.001)$ \\
\hline Годы & Да & Да & Да \\
\hline \multirow[t]{2}{*}{ Константа } & $3.293^{* * *}$ & $7.527^{* * *}$ & $10.884^{* * *}$ \\
\hline & $(0.725)$ & $(0.974)$ & $(1.346)$ \\
\hline Количество наблюдений & 120 & 120 & 119 \\
\hline Скорректированный $\mathrm{R}^{2}$ & 0.868 & 0.755 & 0.799 \\
\hline Residual Std. Error & $0.226(\mathrm{df}=107)$ & $0.303(\mathrm{df}=107)$ & $0.418(\mathrm{df}=106)$ \\
\hline F Statistic & $66.182^{* * *}(\mathrm{df}=12 ;$ & $31.566^{* * *}(\mathrm{df}=12$ & $\begin{array}{r}40.192^{* * *}(\mathrm{df}=12 \\
106)\end{array}$ \\
\hline
\end{tabular}

Примечание: 
Таблица 5

Результаты линейной регрессии:

зависимые переменные- кредиты регионам Ирана, 2009-2013

\begin{tabular}{|c|c|c|c|}
\hline & \multicolumn{3}{|c|}{ Зависимая переменная } \\
\hline & 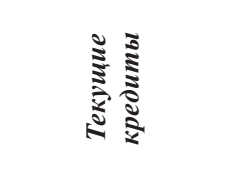 & 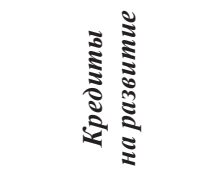 & 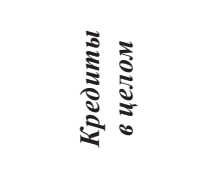 \\
\hline & (1) & (2) & (3) \\
\hline \multirow[t]{2}{*}{ Ахмадинежад, \% } & $-0.005^{* * *}$ & 0.001 & -0.004 \\
\hline & $(0.002)$ & $(0.007)$ & $(0.008)$ \\
\hline \multirow[t]{2}{*}{ Логарифм населения, чел. } & $-0.296^{* * *}$ & $-0.412^{* * *}$ & $-0.708^{* * *}$ \\
\hline & $(0.018)$ & $(0.083)$ & $(0.085)$ \\
\hline \multirow{2}{*}{$\begin{array}{l}\text { Доля трудоспособного } \\
\text { населения, \% }\end{array}$} & 0.002 & -0.028 & -0.026 \\
\hline & $(0.004)$ & $(0.017)$ & $(0.018)$ \\
\hline \multirow[t]{2}{*}{ Безработица, \% } & $0.014^{* * *}$ & -0.006 & 0.008 \\
\hline & $(0.004)$ & $(0.019)$ & $(0.02)$ \\
\hline \multirow{2}{*}{$\begin{array}{l}\text { Логарифм ВBП на душу } \\
\text { населения, млн IRR }\end{array}$} & $0.083^{* * *}$ & $0.267^{* *}$ & $0.350^{* * *}$ \\
\hline & $(0.026)$ & $(0.118)$ & $(0.121)$ \\
\hline \multirow[t]{2}{*}{ Урбанизация, \% } & $-0.005^{* * *}$ & 0.007 & 0.001 \\
\hline & $(0.001)$ & $(0.006)$ & $(0.006)$ \\
\hline \multirow[t]{2}{*}{ Доля нефти в ВВП, \% } & $0.121^{*}$ & 0.47 & $0.592^{*}$ \\
\hline & $(0.07)$ & $(0.318)$ & $(0.329)$ \\
\hline \multirow[t]{2}{*}{ Доля грамотных, \% } & $0.016^{* * *}$ & $-0.06^{* *}$ & -0.044 \\
\hline & $(0.006)$ & $(0.027)$ & $(0.028)$ \\
\hline \multirow[t]{2}{*}{ Доля персов, \% } & $0.089^{* *}$ & 0.278 & $0.367^{*}$ \\
\hline & $(0.044)$ & $(0.199)$ & $(0.205)$ \\
\hline Годы & Да & Да & Да \\
\hline \multirow[t]{2}{*}{ Константа } & $3.04^{* * *}$ & $9.61^{* * *}$ & $12.649^{* * *}$ \\
\hline & $(0.391)$ & $(1.773)$ & $(1.830)$ \\
\hline Количество наблюдений & 120 & 120 & 120 \\
\hline Скорректированный $\mathrm{R}^{2}$ & 0.783 & 0.524 & 0.635 \\
\hline Residual Std. Error & $0.120(\mathrm{df}=107)$ & $0.544(\mathrm{df}=107)$ & $0.562(\mathrm{df}=107)$ \\
\hline F Statistic & $36.744^{* * *}(\mathrm{df}=12$ & $11.928^{* * *}(\mathrm{df}=12$ & $\begin{array}{r}18.223^{* * *}(\mathrm{df}=12 ; \\
107)\end{array}$ \\
\hline
\end{tabular}

Примечание:

${ }^{*} \mathrm{p}^{* *} \mathrm{p}^{* * *} \mathrm{p}<0.01$ 
Ilya Vaskin

\title{
HOW PRESIDENTIAL ELECTION RESULTS EFFECT REGIONAL ECONOMIC SUPPORT IN TUTELARY REGIMES: THE CASE OF IRAN, 2005-2013
}

\begin{abstract}
The goal of this paper is to examine the support role of incumbent candidates of presidential elections on the financing of provinces. This is carried out in the case of Iran over 2005-2013, which is seen as an example of a tutelary regime. The research covers 242 observations including eight years and thirtyone provinces. Core and swing voter theories are employed in the research. The methods used in the paper are correlation and regression analysis. The dependent variables are short- and long-term credits for provinces per capita as well as their sum. Control variables are population, share of employable population, unemployment rate, GDP per capita, urbanization, share of oil in GDP, the share of the population that is Persian ethnically, and change across years. The results showed a significant negative connection between support of the incumbent during presidential elections and current credit lending during the next presidential term. In addition, the research showed an absence of any connection between support of the incumbent during presidential elections and long-term developmental lending for the country`s provinces. Two factors may explain these results. Firstly, the ruling coalition may believe that core voters will give reliable support during elections. As a result of this, more energy is spent trying to win votes of opponents. Secondly, the results can also be explained as connected with attempts to resolve social and economic problems such as poverty, illiteracy, unemployment and so forth, in order to win support in these regions. The results show that incumbent could be oriented at disloyal regions to enlarge the number of constituents by the economic development of provinces. The results may be explained by the rationality of voters. However, the results may be insufficiently represeantative as the research covers only one incumbent and only one tutelary regime.
\end{abstract}

Keywords: elections, financing of regions, Iran, Mahmoud Ahmadinejad, quantitative analysis

DOI: 10.17323/727-0634-2020-18-2-313-330

\section{References}

Alamdari K. (2005) The Power Structure of the Islamic Republic of Iran: Transition from Populism to Clientelism, and Militarization of the Government. Third World Quarterly, 26 (8): 1285-1301.

Ilya Vaskin - Graduate Student, Graduate School of Political Science; Research Intern, Center for Institutional Studies, National Research University 'Higher School of Economics', Moscow, Russian Federation. Email: ivaskin@hse.ru 
Beeman W.O. (2013) Iran's Islamic Republic. In: J.L. Esposito, E.E-D. Shahin (eds.) The $O x$ ford Handbook of Islam and Politics. Cambridge: Cambridge University Press:399-410.

Chen J. (2013) Voter Partisanship and the Effect of Distributive Spending on Political Participation. American Journal of Political Science, 57 (1):200-217.

Constitution (1979) The Constitution of the Islamic Republic of Iran, Adopted by Referendum on 2 and 3 December 1979, amended on 28 July 1989.

Cox G., McCubbins M. (1986) Electoral Politics as a Redistributive Game. The Journal of Politics, 48 (2): 370-389.

Demirkol O., Blotevogel R., Zytek R., Zimand P., Liu Yi. (2014) Islamic Republic of Iran. Selected Issues Paper. IMF Country Report, 14 (94).

Esfahani H. S., Taheripour F. (2002) Hidden Public Expenditures and the Economy of Iran. International Journal of Middle East Studies, (34): 691-718.

Ghobadzadeh N., Rahim L.Z. (2016) Electoral Theocracy and Hybrid Sovereignty in Iran. Contemporary Politics, 22 (4): 450-468.

Golkar S. (2016) Configuration of Political Elites in Post-revolutionary Iran. Brown Journal of World Affairs, 23 (1):281-292.

Guillaume D., Zytek R., Farzin R. M. (2011) Iran - The Chronicles of the Subsidy Reform. IMF Working Papers, 11 (67).

Habibi N. (2015) How Ahmadinejad Changes Iran`s Economy. The Journal of Developing Areas, 49 (1):305-312.

Harris K. (2017) A Social Revolution: Politics and the Welfare State in Iran. Oakland, CA: University of California Press.

Iran Data Portal (2018a) GDP by Province Excluding Oil, Iran (2000-2013). Available at: http://irandataportal.syr.edu/wp-content/uploads/GDP-of-each-province-excluding-oil. xlsx (accessed 25 December 2018).

Iran Data Portal (2018b) GDP by Province, Iran (2000-2013). Available at: http://irandataportal.syr.edu/wp-content/uploads/GDP-of-each-province-1.xlsx (accessed 25.12.2018).

Iran Data Portal (2018c) GDP per capita excluding oil revenues by province, Iran (20002013). Available at: http://irandataportal.syr.edu/wp-content/uploads/GDP-per-capitawithout-oil-2000to2013-1.xlsx (accessed 25 December 2018).

Iran Data Portal (2018d) Presidential Elections (2005). Available at: http://irandataportal.syr.edu/2005-presidential-election (accessed 25 December 2018).

Iran Data Portal (2018 e) Presidential Elections (2009). Available at: http://irandataportal. syr.edu/election-data-2 (accessed 25 December 2018).

Iran Data Portal (2018f) Ethnicity and Religious Services Participation Survey (13881391). Available at: http://irandataportal.syr.edu/ethnicity-and-religious-services-participation (accessed 25 December 208). 
Jawad R., Yakut-Cakar B. (2010) Religion and Social Policy in the Middle East: The (Re) constitution of an Old-new Partnership. Social Policy and Administration, 44 (6): 658-672.

Kamal S.H.M., Rafiey H., Sajjadi H., Rahgozar M., Abbasian E., Sani M. S. (2015) Territorial Analysis of Social Welfare in Iran. Journal of International and Comparative Social Policy, 31 (3):271-282.

Levitsky S., Way L. (2010) Competitive Authoritarianism. Hybrid Regimes After the Cold War. Cambridge: Cambridge University Press.

Lindbeck A., Weibull J. W. (1987) Balanced-budget Redistribution as the Outcome of Political Competition. Public Choice, (52): 273-297.

Marques I.II, Nazrullaeva E., Yakovlev A. (2016) Substituting Distribution for Growth: The Political Logic of Intergovernmental Transfers in the Russian Federation. Economics \& Politics, 28 (1): 23-54.

Rakel E.P. (2009) The Political Elite in the Islamic Republic of Iran: From Khomeini to Ahmadinejad. Comparative Studies of South Asia, Africa and the Middle East, 29 (1): 105-125.

Saleh A. (2013) Ethnic Identity and the State in Iran. Basingstoke: Palgrave MacMillan.

Salehi-Isfahani D. (2006) Revolution and Redistribution in Iran: How the Poor Have Fared 25 Years Later. Available at: https://clck.ru/MnTvK (accessed 25 December 2018).

Statistical Centre of Iran, Management \& Planning Organisation (2011) National Population and Housing Census 2011 (1390): Selected Findings. Available at: http://irandataportal.syr.edu/wp-content/uploads/2011 iran census national-population-and-housingcensus.pdf (accessed 25 December 2018).

Statistical Centre of Iran, Management \& Planning Organisation (2012) Iran Statistical Yearbook 1388 (2009-2010). Available at: http://irandataportal.syr.edu/socio-economicdata/statistical-yearbook (accessed 25 December 2018).

Statistical Centre of Iran, Management \& Planning Organisation (2013 a) Iran Statistical Yearbook 1389 (2010-2011). Available at: http://irandataportal.syr.edu/socio-economicdata/statistical-yearbook (accessed 25 December 2018).

Statistical Centre of Iran, Management \& Planning Organisation (2013b) Iran Statistical Yearbook 1390 (2011-2012). Available at: http://irandataportal.syr.edu/socio-economicdata/statistical-yearbook (accessed 25 December 2018).

Statistical Centre of Iran, Management \& Planning Organisation (2014) Iran Statistical Yearbook 1391 (2012-2013). Available at: http://irandataportal.syr.edu/socio-economicdata/statistical-yearbook (accessed 25 December 2018).

Statistical Centre of Iran, Management \& Planning Organisation (2015) Iran Statistical Yearbook 1392 (2013-2014). Available at: http://irandataportal.syr.edu/socio-economicdata/statistical-yearbook (accessed 25 December 2018).

Stokes S., Dunning T., Nazareno M., Brusco V. (2013) Brokers, Voters and clientelism: The Puzzle of Distributive Politics. Cambridge: Cambridge University Press. 
Simon-Cosano P., Lago-Penas S., Vaquero A. (2013) On the Political Determinants of Intergovernmental Grants in Decentralized Countries: The Case of Spain. Publius: The Journal of Federalism, 44 (1): 135-156.

Veiga L.G., Pinho M. M. (2007) The Political Economy of Intergovernmental Grants: Evidence from a Maturing Democracy. Public Choice, 133 (3/4):457-477. 